\title{
Tribological Characterization of Electrolytic Hard Chrome Coatings
}

\author{
Maroš Eckert ${ }^{1, *}$ \\ Design and Special Technology Department, Faculty of Special Technology, Alexander Dubcek University of Trencin, Ku kyselke 469, 91106 Trencin
}

\begin{abstract}
Electrochemical chromium plating is one of the most widely used surface treatments for metallic materials. This treatment results in a surface layer highly resistant to mechanical wear, temperature and corrosion. In this paper, the experimental material is in the form of a tube made of AISI 304 stainless steel, on the surface of which chromium layers have been deposited by three different companies dealing with electrochemical plating. Tribological tests were performed on a UMT Tribolab device with dry friction of balls made of AISI 52100 steel and $\mathrm{ZrO}_{2}$ ceramics, both with a diameter of $4.762 \mathrm{~mm}$. Measurements were performed at different loads. In the experiments, the courses of friction coefficients were evaluated, and after the measurement, the amount of material removed during friction was determined from the cross-sections of the formed grooves. Furthermore, the influence of the hardness of individual chromium layers and counterparts on tribological behaviour was investigated. The hardness of the counterpart proved to be important, since in the case where the counterpart is softer than the surface layer, the wear was greater than in the opposite situation.
\end{abstract}

Keywords: Chrome layer; Wear; Counterpart; Coefficient of friction

\section{Introduction}

AISI 304 stainless steel has been widely used in the fields of automotive, machinery, nuclear, petrochemical engineering, etc. $[1,2,3]$ due to its excellent combination of strength, ductility and response to good corrosion resistance. However, its further applications have been restricted by its relatively inferior surface hardness. Chromium plating is often used to increase the surface hardness of components manufactured of AISI 304 steel.

Chrome plating the rolls has been a common practice in the steel industry for a long time, both to increase the service life of the roll and to improve strip cleanliness. The high hardness of the chromium coating (up to $1200 \mathrm{HV}$ ) provides higher abrasion resistance, which helps to increase roll lifetime [4]. Additionally, it helps against adhesive transfer for sticky alloys $[5,6,7]$. It is reported that chrome plating could make a difference of up to $20 \%$ in reflection tape value, a method used to quantify iron fines generated $[3,8]$. Although its positive influence on strip cleanliness has been known, there are only few studies on the governing mechanisms why this coating improves strip cleanliness. In general, there are two types of chromium plating, namely decorative, in which the thin coating serves as a glossy and durable surface treatment. The second type is industrial or hard chromium, in which it uses a chromium coating for its advantageous properties such as resistance to heat, wear, corrosion and erosion, abrasion and low coefficient of friction. The difference between decorative and hard chrome is not only in the purpose of its use, but also in the different thickness of the chrome layer. In the case of decorative chromium, this layer ranges from 0.5 to $2 \mu \mathrm{m}$, in the case of hard chromium, the standard layer thickness is from 10 to $250 \mu \mathrm{m}$ [9]. The 
use of hard chromium is used not only on steel, but preferably also on other metallic materials to form a durable surface layer [10]. Electrolytic chromium plating is an important means of extending the life of all types of metal parts that are exposed to wear, friction, abrasion, and corrosion. Such components may have protected functional surfaces with a chromium layer, whereby after wear of such surfaces it is possible to re-form a chromium layer which either immediately or after further processing meets the original properties and tolerances. Because hard chromium has a low surface energy, it is often used on sliding or rotating parts of motors, pumps, compressors and hydraulic or pneumatic piston rods [11]. Another advantage is its high corrosion resistance, which makes it widely used to protect the surfaces of parts exposed to various highly corrosive environments [12]. Furthermore, it is advantageous that the chromium plating process is relatively cold and can therefore be used to increase the hardness of the surfaces of very small parts without the risk of thermal deformation or a change in the properties of the base material. Hard chromium coatings achieve a hardness in the range of 56 to 74 HRC depending on the electrolytic bath used. In most cases, the greater the hardness, the longer the life of the component. Therefore, it is best to use a plating process that provides the highest hardness. A component with a hardness of up to $70 \mathrm{HRC}$ will provide the longest possible service life.

In this case, the base material is austenitic stainless steels AISI 304, which is known for its good corrosion resistance and formability $[13,14]$. The effects of grain size and martensitic transformation of the wear behavior have already been investigated elsewhere [15]. The quality of the chromium layer in terms of tribological properties depending on the crack density was investigated by the authors [16] using only a steel ball. The effect of base material hardness on wear and wear regime transition has been investigated by many authors, including [17], who examined in detail the worn surface and coefficient of friction in pin-on-disk tests. The study of tribological properties in contact with steel and ceramic balls was investigated by the authors [18]. In their work, they focused on obtaining the dependence between wear rate and hardness of the chromium layer. Their results show that in the case of the steel ball, the wear decreased with increasing hardness of the chromium layer, while in the case of the ceramic ball, the wear increased at higher hardness. They attribute this fact to another wear mechanism, where in the case of a ceramic ball, which is significantly harder than the chromium layer, significant abrasive wear is expected, in contrast to steel, where the predominant wear mechanism should be adhesive. However, all authors have studied the chromium layer formed on a flat surface, but in practice there are many cases where the chromium layer is deposited on a cylindrical surface and thus other contact conditions occur, which can affect wear and especially the coefficient of friction. Due to the possibility of comparing different chromium layers, three different chromium layers were deposited on the same base material and the results were compared with the wear of the base material without coating. By determining the size of the wear and the coefficient of friction, it was possible to qualitatively determine the best layer in terms of durability and resistance to movement of counterparts.

\section{Materials and methods}

Stainless steel AISI 304 was used as a substrate material supplied in the form of cold drawn tubes tempered to $850 \mathrm{MPa}$. The outer diameter of the pipe $12.3 \mathrm{~mm}$ was then ground to a diameter of $12 \pm 0.005 \mathrm{~mm}$ and the same roughness value max. $\mathrm{Rz}=3 \mu \mathrm{m}$, an inner diameter was $9.3 \mathrm{~mm}$. The nominal chemical composition is in Tab. 1. Electroplated hard-chrome coatings with a thickness of min. $30 \mu \mathrm{m}$ were applied to the outer surface of the pipe in three different industrial plants according to the specific company procedure and the experience of a particular company.

The tribological properties were investigated in a ball-on-tube test, in which the ball moved along the path ( $\mathrm{L}$ ) of $10 \mathrm{~mm}$ with a frequency of $1 \mathrm{~Hz}$ after the $\mathrm{Cr}$ coating of the pipe surface (Fig. 1). A bearing ball made of AISI 52100 with a hardness of 1145 HV100 and a ceramic ball with a hardness of 1700 HV100 were used as a counterpart. Both beads had a diameter of $4.762 \mathrm{~mm}$. The tests were performed for loads (F) of $10 \mathrm{~N}, 30 \mathrm{~N}$ and $50 \mathrm{~N}$ and a sliding time of $4000 \mathrm{~s}$ was selected for each test. The specimens were cleaned with ethyl alcohol before each test to prevent unwanted surface contamination. Tribological measurements were performed on a Bruker UMT TriboLab in a climate-controlled room at a temperature of $20^{\circ} \mathrm{C}$ and a humidity of $60 \%$. Each specimen was tested three times under the 
Table. 1: Chemical composition of AISI 304 stainless steel tube used as a substrate material

\begin{tabular}{|l|l|l|l|l|l|l|l|l|l|l|l|l|}
\hline Element & $\mathrm{Cr}$ & $\mathrm{Ni}$ & $\mathrm{Mn}$ & $\mathrm{Mo}$ & $\mathrm{Si}$ & $\mathrm{C}$ & $\mathrm{Co}$ & $\mathrm{P}$ & $\mathrm{S}$ & $\mathrm{Cu}$ & $\mathrm{V}$ & Fe \\
\hline [Wt \%] & 17.35 & 8.52 & 0.98 & 0.18 & 0.45 & 0.03 & 0.21 & 0.02 & 0.003 & 0.19 & 0.08 & Remain \\
\hline
\end{tabular}

same condition to collect an average value. After the measurement, images were taken using a builtin optical microscope to determine the width and morphology of the groove. Wear was determined from the groove geometry as the amount of material removed $\left(\mathrm{mm}^{3}\right)$ divided by the product of the load $(\mathrm{N})$ and the total sliding distance $(\mathrm{m})$. The coefficient of friction was measured and determined directly by a tribotesting device throughout the test.

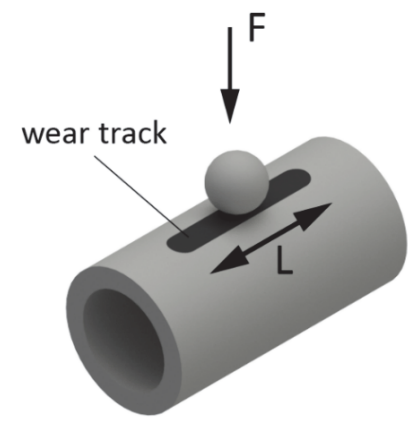

Figure 1: Tribological test configuration

\section{Results and Discussion}

The magnitude of the wear of the chromium layer on the steel ball as a counterpart for the individual chromium coatings and loads is shown in Fig. 2a. For comparison, Fig. 2b additionally shows the wear in the case of the base material, where the wear rate is in a logarithmic scale for better graph readability. As expected, the greatest wear is in the case of the base material and decreases for each sample with decreasing load. From the microstructure of wear tracks it can be seen that in the case of chromium layers the primary wear is mainly formed by adhesion wear, in the case of the base material the most significant wear is formed by plow-abrasion wear. In the case of chromium layers, the greatest wear is shown by the coating $A$, on the contrary, the smallest one by the coating $C$. This can also be seen from Fig. 3, where the chrome layer contains the widest trace in the coating $\mathrm{A}$. This result is interesting because from the cross-section images of the layers, the coating A appeared to be of the highest quality.

In the case of the coatings $B$ and $C$, the softer contact is on the side of the chromium layer, but already in the case of the coating $A$, the softer contour (a)

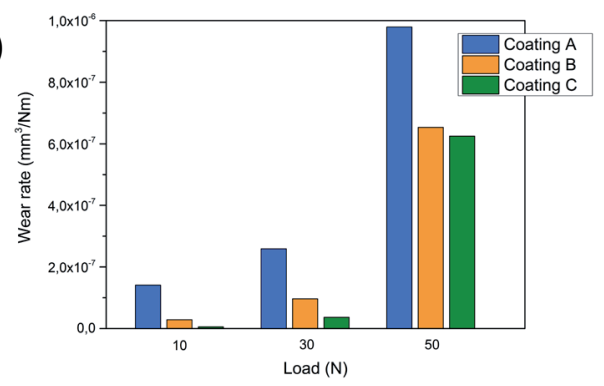

(b)

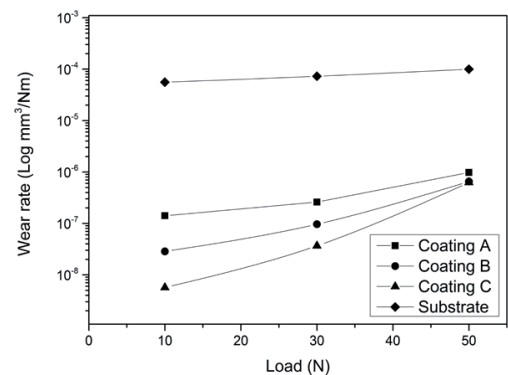

Figure 2: (a) Wear rate of hard-chrome coatings sliding against the steel ball. (b) Wear rate of hard-chrome coatings and substrate material sliding against the steel ball

is on the side of the ball. It follows that the selection and evaluation of the chromium layer can not only be carried out based on its microhardness, but it is also necessary to perform wear tests. In the nature of chrome layers and a steel ball as a counterpart, it could not be identified a significant wear even after $4000 \mathrm{~s}$, in contrast to the wear test on the substrate material, where the dominant wear was caused by abrasive wear. In comparison, at a load of $10 \mathrm{~N}$, the wear in the case of the base material is up to 1000 times greater than in the case of the coating $\mathrm{C}$, but even at a load of $50 \mathrm{~N}$ it is only about 160 times.

In the case of wear when using a ceramic ball as a counterpart, the wear of the chromium layer was significantly greater. Fig. 4 shows a wear track at a load of $50 \mathrm{~N}$, where the dominant wear is formed by an abrasive wear mechanism, which is caused by the formation of very hard particles between the sliding surfaces. In the case of the cross-section view, it can be seen that the chromium layer has been completely removed down to the base material. Such rapid wear is probably also due to the delamination wear mechanism of the chromium layer, and abrasive wear of the base material has already 
begun [12]. Violation of the chromium layer up to the base material was observed at all coatings at a load of $50 \mathrm{~N}$ and a sliding time of $4000 \mathrm{~s}$.

(a)

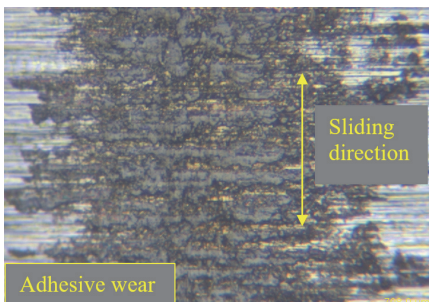

(b)

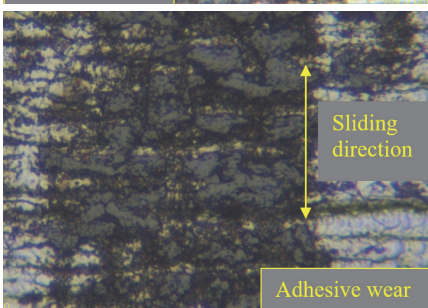

(c)

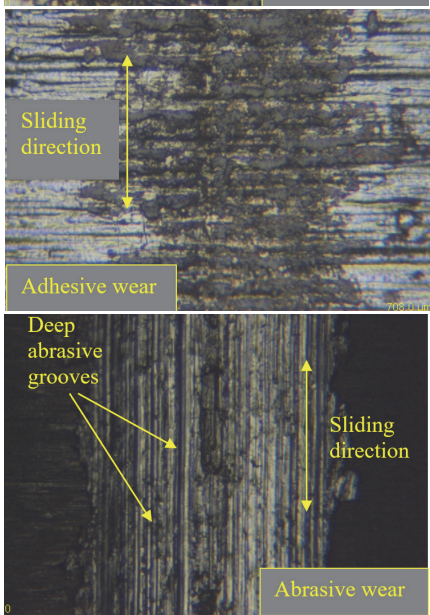

Figure 3: Optical microstructure of wear tracks sliding against the steel ball at $50 \mathrm{~N}$ load and $4000 \mathrm{~s}$ sliding time: (a) Coating A.

(b) Coating B. (c) Coating C. (d) Substrate material.

Fig. 5 depicts the coefficient of friction as a function of the sliding time for the hard chrome coating sliding against the steel and ceramic ball at a load of $50 \mathrm{~N}$. It is visible that the coefficient of friction during the sliding time varied in the initial stages and later stabilized at values that can be considered as the steady-state coefficient of friction. Fig. 5a shows the relationship between friction coefficient and sliding time for three hard-chrome variants sliding against steel ball and load of $50 \mathrm{~N}$. In the case of the coating $A$, the initial friction coefficient was the highest and also reached the highest steady-state coefficient, namely 0.8 . The friction was greatest de- (a)

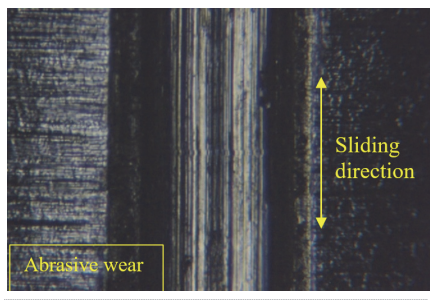

(b)

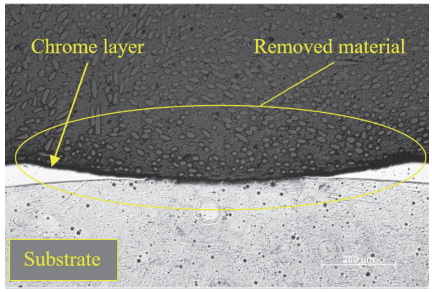

Figure 4: Optical microstructure of wear track sliding against the ceramic ball at $50 \mathrm{~N}$ load for $4000 \mathrm{~s}$ sliding time: (a) Top view on the wear track (coating $A$ ). (b) Cross-section view on the wear track (coating $A$ ).

spite the roughness of this coating being the smallest. Such behaviour occurs if the polishing wear process is able to remove the contaminating layers, then the elements of the bare surface will appear, resulting in an increase in the coefficient of friction due to increased adhesion.

A similar course can be seen in the case of the coatings $B$ and $C$, with the difference that the increase in the friction coefficient was not as sharp as in the coating A. In the case of the ceramic ball, the course of the friction coefficient is however different (Fig. 5b). After the initial phase, when the coefficient of friction increases only slightly, there is a sharp break and a rapid increase in friction. In the case of the coatings $A$ and $B$, this break is relatively fast, in the case of the coating $C$, this break occurs only after a longer sliding time. After a sharp increase in the coefficient, a peak value is reached, in the range of 0.6 to 0.7 . The highest value of the peak value of the coefficient is reached by the coating $A$, as in the case of a steel ball as a counterpart. Achieving the steady-state coefficient of friction occurs significantly earlier than in the case of the steel ball, already after $750 \mathrm{~s}$ in the case of the coating $\mathrm{A}$ and its value is similar for all coatings in the range from 0.45 to 0.6. In this case, it is unlikely that adhesive wear has occurred due to the different crystal structure between the base material and the counterpart. The significant increase in the coefficient of friction was due to the rapid increase in the number of wear particles entrapped between the sliding surfaces 
as a consequence of higher wear rates. After some time, the wear and friction coefficient stabilized due to the increase in contact surface and reduction for creating new particles, which cause plowing.

(a)

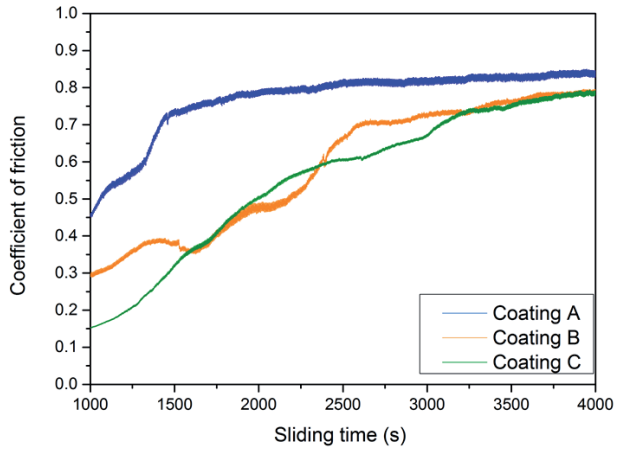

(b)

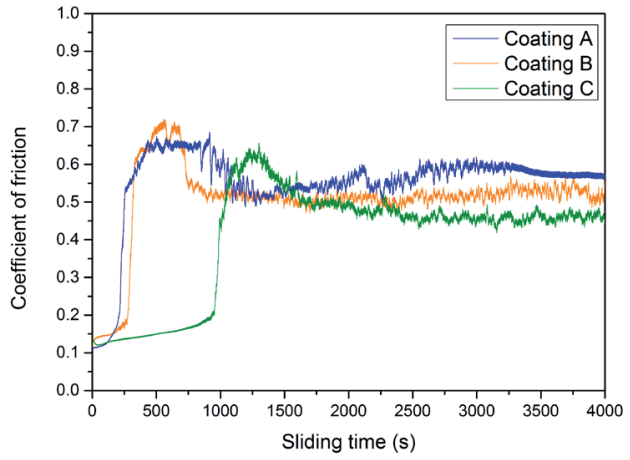

Figure 5: Coefficient of friction vs. sliding time for the hardchrome coating sliding against: (a) Steel ball (Load 50 N). (b) Ceramics ball (Load 50N).

\section{Conclusions}

This work was focused on investigating the influence of different chromium layers deposited on the AISI 304 material on tribological behaviour during dry sliding tests. Counterparts in the form of balls made of AISI 52100 steel and $\mathrm{ZrO}_{2}$ ceramic were used for the measurements.

The wear of the base material compared to the chromium layers was in the case of a steel ball as a counterpart and a load of $10 \mathrm{~N}$ to 1000 times greater, but this difference decreased with an increasing load. For the chromium layers and the steel ball, it was found that the greatest wear was achieved with the layer with the highest surface microhardness (the coating A), which was greater than the hardness of the ball. This probably caused more wear on the ball, increased the contact area, removed deburds to push into the ball, and created an abrasive that increased adhesive wear.
In the case of the ceramic ball as a counterpart, there was a predominantly abrasive wear, mainly due to the different crystalline structure of the contact materials. The wear was already in accordance with the Archard's law and decreased with increasing surface microhardness of the layer. When comparing the coefficients of friction, it was found that in the case of the steel ball as a counterpart, the onset to the steady-state value of the coefficient of friction is gradually increasing. In the case of the ceramic ball, the peak value of the coefficient is reached at the beginning and the coefficient of friction gradually decreases to a steady-state value. On average, lower values of the coefficient of friction were obtained in the case of the ceramic ball. The coefficient of friction significantly depends on the value of the contact pressure, and in all chromium layers it has been shown that the coefficient of friction increases with an increasing contact pressure.

\section{Acknowledgments}

This work was also supported by the Research Agency of the Ministry of Education, Science, Research and Sport of the Slovak Republic under the contract (ITMS2014+) no. 313011W442CEDITEK II.

\section{References}

1. Wang, H.B., Song, G.L., Tang, G.Y. (2016). Effect of electropulsing on surface mechanical properties and microstructure of AISI 304 stainless steel during ultrasonic surface rolling process. Materials Science and Engineering: A, 662, 456-467.

2. Tao, N.R., Sui, M.L., Lu, J. (1999). Surface nanocrystallization of iron induced by ultrasonic shot peening. Nanostructural Materials, 11, 433-440.

3. Zhang, H.W., Liu, G., Hei, Z.K., Lu, J., Lu, K. (2003). Surface nanocrystallization of AISI 304 stainless steel induced by surface mechanical attrition treatment structure and property. Acta Metallurgica Sinica, 39, 342-346.

4. Simão, J., Aspinwall, D.K. (1999). Hard chromium plating of EDT mill work rolls. Journal of Materials Processing Technology, 92-93, 281-287.

5. De Mello, J.D.B., Gonçalves, J.L., Costa, H.L. (2013). Influence of surface texturing and hard chromium coating on the wear of steels used in cold rolling mill rolls. Wear, 302, 12951309.

6. Montmitonnet, P., Bouadjadja, N., Luong, L.P., Bertrandie, J.J., Dietsch, H. (2018). On the mechanism by which chromium improves strip surface cleanliness in steel strip cold rolling. Key Engineering Materials, 767, 240-247. 
7. Chiu, L.H., Yang, C.F., Hsieh, W.C., Cheng, A.S. (2002). Effect of contact pressure on wear resistance of AISI H13 tool steels with chromium nitride and hard chromium coatings. Surface Coating Technology, 154, 282-288.

8. Jacobs, L., et al. (2011). Improving strip cleanliness after cold rolling. Proceedings of the Institution of Mechanical Engineers, Part J, 225, 959-969.

9. Plating Resources (2006). DuraChrome Hard Chromium Plating. Cocoa, Florida.

10. Peciar, M., Fekete, R., Peciar, P. (2016). Agglomeration technologies of processing powder wastes. Solid State Phenomena, 244, 121-129.

11. Fekete, R., Peciar, M., Peciar, P. (2018). Axial extruder with rotatable die head. WIPO, 2015: WO2015159198A1.

12. Kapps, V., Almeida, C.M., Trommer, R.M., Senna, C.A., Maru, M.M. (2019). Scatter in delamination wear tests of tribopair materials used in articulated implants. Tribology International, 133, 172-181.

13. Bell, T. (2002). Surface engineering of austenitic stainless steel. Surface Engineering, 18, 415-422

14. Hashemi, B., Yazdi, M. R., Azar V. (2011). The wear and corrosion resistance of shot peened-nitrided 316L austenitic stainless steel. Materials and Design, 32, 3287-3292.

15. Dehsorkhi R.N., Sabooni S., Karimyadeh, F., Reyaeian, A., Enayati, M.H. (2014). The effect of grain size and martensitic transformation on the wear behavior of AISI $304 \mathrm{~L}$ stainless steel. Materials and Design, 64, 56-62.

16. Podgornik, B., Massler, O., Kafexhui, F., M. Sedlacek. (2018). Crack density and tribological performance of hard-chrome coating. Tribology International, 121, 33-340.

17. Viáfara, C.C., Sinatora, A. (2009). Influence of hardness of the harder body on wear regime transition in a sliding pair of steel. Wear, 267, 425-432.

18. Zhixiang, Z., Liping, W., Chen, L., Junyan, Z. (2006). The correlation between the hardness and tribological behaviour of electroplated chromium coatings sliding against ceramic and steel counterparts. Surface and Coating Technology, 201, 2282-2288. 